\title{
Factors associated with vaginal birth after previous cesarean section in Brazilian women
}

\author{
José Guilherme Cecatti, ${ }^{1}$ Helaine Maria Besteti Pires, ${ }^{1}$ Aníbal Faúndes, ${ }^{1}$ \\ and Maria José Duarte Osis²
}

Suggested citation Cecatti JG, Pires HMB, Faúndes A, Duarte Osis MJ. Factors associated with vaginal birth after previous cesarean section in Brazilian women. Rev Panam Salud Publica. 2005;18(2):107-13.

ABSTRACT Objective. To identify factors associated with a vaginal second delivery in women who had one previous cesarean section.

Methods. A nested case-control study was carried out as a secondary data analysis of an original retrospective, population-based cohort study of women who delivered their first child during 1985 in the city of Campinas, São Paulo, Brazil, and who were interviewed 10 years later in 1995. The study population consisted of 1352 women who had their first delivery by cesarean section and who had also had at least one subsequent delivery. The group of cases (150 women, around $11 \%$ of the sample) consisted of women who had a vaginal second delivery, and the control group was made up of 1202 women who had a cesarean section at second delivery. For each possible associated factor we calculated the odds ratio and $95 \%$ confidence interval. For ordered categorical variables the $\mathrm{c}^{2}$ test for trend was used. Unconditional multivariate regression analysis was used to estimate the adjusted odds ratio for each associated factor.

Results. The factors significantly associated with vaginal delivery were monthly family income below 5-fold the Brazilian minimum monthly wage, reliance on the Brazilian national health system for healthcare, low maternal age, and first cesarean section indicated because of fetal breech or transverse presentation, or twin pregnancy. Among those women who also had a cesarean section at their second delivery, only $11 \%$ had undergone a trial of labor.

Conclusions. The main determining factors for a vaginal second delivery in women with a previous cesarean section were unfavorable social and economic factors.

Key words Cesarean section; vaginal birth after cesarean; risk factors; trial of labor.

Cesarean section (C-section) is the most frequent surgical intervention worldwide. Although commonplace today, this intervention was severely restricted in the past (1). However, as

\footnotetext{
1 Department of Obstetrics and Gynecology, University of Campinas, Brazil. Send correspondence and reprint requests to J.G. Cecatti, P.O. Box 6030,13081-970 Campinas-SP, Brazil; fax: +55 19 37889304; e-mail: cecatti@unicamp.br .

2 Center for Research in Maternal and Child Health of Campinas (CEMICAMP), Campinas, Brazil.
}

soon as the mortality and morbidity associated with C-sections decreased, indications for this surgical procedure increased. With the onset and evolution of anesthetic techniques during the previous century, and the development of antibiotic therapy in the 1960s, maternal mortality after Csection reached a stable level of $0.2 \%$ in California and $0.13 \%$ in Great Britain. In 1985, maternal mortality after C-section was estimated to be below 1 per 1000 (2). This increase in safety encouraged obstetricians to find more and more reasons for carrying out this operation.

However, there are still complications associated with this procedure. Maternal morbidity associated with C-section is five to ten times greater than that associated with vaginal delivery $(2,3)$. Maternal deaths consid- 
ered to be caused by the procedure have been estimated at 5.8 to 59 per million C-sections (4). In one USA review, the only category in which maternal mortality did not decline during the 1970s was repeated cesarean deliveries, where the mortality rate was four times as great as for uncomplicated vaginal deliveries (5).

One of the justifications for increasing the number of $\mathrm{C}$-sections was the possible benefit to the fetus. Today, however, it is clear that the main determining factors in reducing neonatal morbidity and mortality are the development of neonatal intensive care units and the improvement in maternal health, neither of which is necessarily affected by the mode of delivery (2).

Currently, one in every five pregnant women in the USA delivers by Csection. This is an issue that requires a more careful analysis to identify factors that influence the choice of route of delivery $(6,7)$. If this is the situation in a developed country such as the USA, the implications may be far more dramatic in a country such as Brazil, where one in every three women (and in many regions one in every two or two in every three women) have their children by C-section (3).

Apart from the evident repercussions caused by cesarean delivery in terms of maternal and perinatal morbidity and mortality, the costs associated with this type of intervention are extremely high. Data collected in 1987 estimated that, for that year, around 475000 unnecessary cesarean deliveries were carried out in the USA, causing 25 to 100 maternal deaths, nearly 25000 severe maternal infections and 1.1 million days of hospitalization, resulting in an additional cost of more than US\$ 1 billion (2).

A cesarean section at first delivery results in a routine of repeated abdominal deliveries (8). The significance and possible future repercussions of a uterine scar are not sufficiently emphasized when the indications for the first cesarean section are explained to the woman. The scar and its associated morbidity can influence the woman's reproductive future $(3,9,10)$; moreover, maternal morbidity and mortal- ity are significantly lower in patients who have a vaginal delivery $(3,6,11)$.

In Brazil nonmedical factors play an important role in the decision of whether or not to perform a C-section. Until 1980, the National Health System (INPS/SUDS, hereafter NHS) paid physicians more for performing a C-section than for carrying out a vaginal delivery, and this fact may have encouraged doctors to choose abdominal deliveries. After 1980 this policy changed and payment became the same for both modes of delivery. Nevertheless, $\mathrm{C}$-section rates continued to increase by $24 \%$ to $29 \%$ in the four years subsequent to this change, suggesting an influence of other factors (12-14). These factors are associated with sociocultural, economic, medical and institutional aspects and explain the preference of some women and their physicians for an abdominal delivery $(8,15,16)$.

The purpose of the present study was to identify medical and other related factors associated with vaginal birth after a C-section (VBAC) for the previous delivery. The identification of these factors could help change the present situation, reducing C-section rates and consequently reducing maternal and neonatal morbidity, which would lead to a reduction in the costs of maternal and neonatal hospital care.

\section{METHODS}

This is a nested case-control study carried out as a retrospective secondary analysis of a population-based cohort study performed in Campinas, São Paulo, Brazil (14). In the original cohort, all women who had their first delivery in Campinas (741 500 inhabitants in 1985) between January 1 and December 31, 1985 were selected as the study population. Data on their reproductive history were collected during a personal interview performed 10 years later, in 1995, when they entered the cohort. These women were identified by contacting all the 10-year-old children attending all the schools in the city. This research protocol was approved by the Institutional Review
Board of the University of Campinas prior to initiation of the study, and the women agreed verbally to take part in the study before the interview.

The data from the original cohort study contains information for approximately 3885 women. Of these, 1352 women who had their first delivery in 1985 by C-section and who had also had at least one more delivery were selected for the present analysis. They were divided into two groups according to the mode of the second delivery. For the present study we used data from all 150 women who delivered their second child vaginally (cases) and all 1202 women who had a C-section (controls). Therefore, there was no random selection of cases and controls; all cases and controls available in the cohort database were used for this analysis.

The sample size was calculated considering family monthly income as the main predictive factor. Because $15 \%$ of the cases and $37 \%$ of the controls were part of a household with a monthly income greater than 15 -fold the minimum monthly wage, a minimum of 141 cases was required for an alpha error of 0.05 and a beta error of 0.05 .

The following variables were evaluated: mode of second delivery, maternal age at second delivery, schooling, marital status, family income, type of health insurance, race, trial of labor during first delivery, trial of labor during second delivery, health of their first child, clinical and obstetrical conditions of the second pregnancy, gestational age, and whether or not tubal ligation was done.

An experienced interviewer specially trained in the use of a specific questionnaire obtained data for all participants in the original protocol. The questionnaire had been specially formulated for the cohort study and contained items regarding personal data, sociodemographic characteristics, and detailed information on their reproductive history (including all deliveries and abortions during the 10year period) and contraceptive use between pregnancies. The questionnaire had been pretested in a pilot study in a subsample of women who were not in- 
cluded in the final analysis. Data from this original file were used to build a new database, which was then used for the present study.

Initially, univariate analysis was done with the chi-squared trend test for ordered categorical variables. Odds ratios (OR) and their 95\% confidence intervals (Cornfield or exact method) were also calculated. Multivariate analysis was done using unconditional logistic regression to control for the confounding effect of using many variables, and adjusted OR were calculated. The SPSS-PC+ software program (v. 11.5) was used for all statistical analysis.

\section{RESULTS}

Of the 1352 women initially eligible for inclusion, all were included in the current analysis. The 150 women whose second delivery was vaginal constitute the population of cases, representing a general VBAC rate of $11 \%$. The control population was made up of the 1202 remaining women whose second delivery was by C-section, resulting in a proportion of 8 controls to each case. Of the 333 women who underwent a trial of labor during the second delivery, 45\% (150) delivered vaginally. This VBAC rate reflects the success that can be achieved by performing a trial of labor in women with a previous abdominal delivery. Among women in the control group who delivered by C-section, only $15.2 \%$ (183) underwent a trial of labor during the second delivery (data not shown). The data specifically for the subset of women in whom labor was attempted is the subject of another paper (14).

With respect to the age of patients at second delivery, the estimated risk of women having a vaginal delivery decreased as age increased, and this trend was significant. Regarding literacy, the estimated risk of vaginal delivery increased as the educational level of the patients decreased, and this trend was also highly significant. We also observed a highly significant association between medical insurance coverage and route of delivery. Women who relied on the National Health System to cover the costs of their second delivery had a higher risk of delivering vaginally than those covered by private insurance schemes. There was also a strong association between monthly family income and mode of delivery. The estimated risk for a woman with a previous $\mathrm{C}$-section of having a vaginal second delivery decreased as family income increased, and this trend was also highly significant. Marital status and non-white skin color were also associated with vaginal birth (Table 1).

Among the obstetrical indications that motivated a first cesarean delivery, fetal-related complications, breech presentation and twin gestation had the highest significant estimated risks of vaginal delivery for the second

TABLE 1. Sociodemographic factors associated with vaginal delivery after previous Cesarean section in 1352 women in Campinas, SP, Brazil, 1985-1995

\begin{tabular}{|c|c|c|c|c|}
\hline \multirow[b]{2}{*}{ Factors } & \multicolumn{2}{|c|}{ Route of delivery } & \multirow{2}{*}{$\begin{array}{l}\text { Odds ratio for } \\
\text { vaginal delivery }\end{array}$} & \multirow[b]{2}{*}{$95 \% \mathrm{Cl}$} \\
\hline & Vaginal & Cesarean & & \\
\hline \multicolumn{5}{|l|}{ Age (years) ${ }^{a}$} \\
\hline$\leq 19$ & 3.2 & 14.0 & 1.00 & - \\
\hline $20-24$ & 24.0 & 42.7 & 0.40 & $0.21-0.76$ \\
\hline $25-29$ & 41.3 & 25.3 & 0.14 & $0.07-0.27$ \\
\hline $30-34$ & 23.4 & 14.7 & 0.14 & $0.07-0.30$ \\
\hline$\leq 35$ & 8.2 & 3.3 & 0.09 & $0.03-0.28$ \\
\hline \multicolumn{5}{|l|}{ Schooling ${ }^{b}$} \\
\hline University level & 10.7 & 25.0 & 1.00 & - \\
\hline High school & 8.7 & 23.5 & 0.86 & $0.38-1.93$ \\
\hline $5-8$ years of schooling & 43.3 & 32.5 & 3.13 & $1.72-5.75$ \\
\hline $1-4$ years of schooling & 36.0 & 18.2 & 4.64 & $2.50-8.69$ \\
\hline None & 1.3 & 0.7 & 4.70 & $0.45-26.23$ \\
\hline \multicolumn{5}{|c|}{ Health insurance used at the second delivery ${ }^{c}$} \\
\hline Paid privately & 6.0 & 14.1 & 1.00 & - \\
\hline Medical insurance & 26.8 & 64.9 & 0.97 & $0.44-2.18$ \\
\hline National health system & 67.1 & 20.9 & 7.48 & $3.55-16.31$ \\
\hline \multicolumn{5}{|c|}{$\begin{array}{l}\text { Monthly family income } \\
\quad(\text {-fold minimum monthly wage })^{d}\end{array}$} \\
\hline$\leq 5$ & 49.6 & 17.6 & 1.00 & - \\
\hline $6-10$ & 28.8 & 29.0 & 0.35 & $0.22-0.55$ \\
\hline $11-15$ & 6.5 & 15.9 & 0.14 & $0.06-0.31$ \\
\hline$\geq 16$ & 15.1 & 37.5 & 0.14 & $0.08-0.25$ \\
\hline Unmarried & 36.7 & 16.5 & 2.94 & $2.00-4.30$ \\
\hline Non-white & 44.7 & 32.3 & 1.69 & $1.18-2.42$ \\
\hline Total & 150 & 1202 & & \\
\hline
\end{tabular}

pregnancy. Other factors identified by univariate analysis as being associated with a VBAC were rupture of membranes in the second pregnancy and absence of hypertension. The risk of a vaginal delivery among women who had undergone a trial of labor prior to the first C-section was greater, but this difference did not reach statistical significance. We observed no association between the health status of the first child and the mode of second delivery, or between gestational age in the current pregnancy and mode of delivery (Table 2).

In addition to evaluating factors associated with vaginal delivery, we also tried to analyze whether the route of delivery modified neonatal health as reported by the mother. We observed no significant difference in neonatal health after the second delivery be- 
TABLE 2. Health and healthcare factors related with vaginal delivery after a cesarean section in 1352 women in Campinas, SP, Brazil, 1985-1995

\begin{tabular}{lrrrr}
\hline \multicolumn{1}{c}{ Factor } & Vaginal & Cesarean & Odds ratio & 95\% Cl \\
\hline Indication for the first cesarean section & & & & \\
$\quad$ Other indications & 68.7 & 83.9 & 1.00 & - \\
$\quad$ Breech presentation & 21.3 & 11.6 & 2.25 & $1.42-3.55$ \\
$\quad$ Twin pregnancy & 3.3 & 0.4 & 9.79 & $2.20-43.10$ \\
$\quad$ Transverse presentation & 6.7 & 4.2 & 1.96 & $0.90-4.14$ \\
Not breech or transverse presentation or & & & & \\
$\quad$ twins in second delivery & 93.3 & 88.7 & 1.79 & $0.89-3.70$ \\
Diabetes in second pregnancy & 2.7 & 1.3 & 2.03 & $0.57-6.58$ \\
Hypertension in second pregnancy & 8.7 & 16.1 & 0.50 & $0.26-0.92$ \\
Rupture of membranes in second pregnancy & 36.0 & 19.6 & 2.31 & $1.58-3.38$ \\
Hemorrhage in second pregnancy & 5.3 & 7.3 & 0.71 & $0.31-1.56$ \\
Poor health of first child at birth & 5.3 & 5.5 & 0.97 & $0.42-2.14$ \\
Term pregnancy & 88.7 & 89.0 & 0.97 & $0.55-1.71$ \\
Trial of labor prior to first cesarean & 39.3 & 31.7 & 1.40 & $0.97-2.01$ \\
Total & 150 & 1202 & & \\
\hline
\end{tabular}

TABLE 3. Factors found in multivariate logistic regression analysis to be statistically associated with vaginal delivery after a cesarean section in 1352 women in Campinas, SP, Brazil, 1985-1995

\begin{tabular}{lccccr}
\hline \multicolumn{1}{c}{ Factor } & Coefficient & $\begin{array}{c}\text { Standard } \\
\text { error }\end{array}$ & $\begin{array}{c}\text { Adjusted } \\
\text { odds ratio }\end{array}$ & $P$ & $95 \% \mathrm{Cl}$ \\
\hline $\begin{array}{l}\text { National health system coverage only } \\
\begin{array}{l}\text { Monthly family income } \leq 5 \text {-fold the } \\
\quad \text { minimum monthly wage }\end{array}\end{array}$ & 1.5431 & 0.2349 & 4.68 & $<0.001$ & $2.97-7.41$ \\
$\begin{array}{l}\text { First cesarean due to breech or } \\
\quad \text { ransverse presentation, or twins }\end{array}$ & 1.0198 & 0.2324 & 2.77 & $<0.001$ & $1.76-4.37$ \\
$\begin{array}{l}\text { Maternal age at 2nd delivery } \\
\text { No breech or transverse presentation } \\
\quad \text { or twins in the second delivery }\end{array}$ & 0.8470 & 0.2518 & 2.33 & $<0.001$ & $1.42-3.82$ \\
\begin{tabular}{l} 
Constant \\
\hline
\end{tabular} & 1.0912 & 0.4987 & 2.98 & 0.008 & $1.12-7.91$ \\
\hline
\end{tabular}

tween the two modes of delivery: women reported poor health status in the child in $6.8 \%$ of the cases and in $6.2 \%$ of the controls (data not shown).

Multivariate analysis showed that the factors that had the largest independent associations with VBAC were reliance on the Brazilian NHS health system for healthcare, low family income, no breech or transverse presentation or twin pregnancy at second delivery, first C-section indicated because of breech or transverse presentation or twin pregnancy, and younger maternal age (Table 3).

Of the 1352 women studied, 350 (25.9\%) underwent tubal ligation during the second delivery. Of these insurance and only $6 \%$ relied on the NHS. However, women who had a tubal ligation, even those who used medical insurance or the NHS, mentioned having to pay extra for the procedure (data not shown).

\section{DISCUSSION}

High C-section rates are a worldwide problem, particularly in Brazil and other Latin American countries where the numbers are alarming. This study was carried out with the objective of identifying the factors associated with the high rates of C-section in Brazil, in particular in the extremely common situation of pregnant women who had already had a previous C-section. The results showed that the main factors associated with a vaginal second delivery were not medical but essentially less favorable sociodemographic characteristics including young maternal age, low level of literacy and low family income. These factors basically represent the social and economic determinants of mode of delivery, a well-known phenomenon in Brazil. There is probably also a relationship between family income, type of health insurance and educational level; however we did not perform specific tests of interaction between these variables because we considered the multivariate analysis to be sufficient. In fact, this analysis identified only family income and type of health insurance as showing a strong independent association with the mode of second delivery.

The first conclusion that can be drawn from this study is that, generally speaking, the factors associated with a vaginal second delivery were similar to those associated with attempted labor (14), and include low monthly family income, access only to general medical insurance through the NHS, low maternal age, and rupture of the membranes during the second delivery (14). This is exactly what we expected to find, and these results support the hypothesis that the only way for a pregnant woman with a previous abdominal delivery to have a vaginal delivery for a subsequent pregnancy is 
to allow her to undergo a trial of labor. In fact, there is no scientific evidence that the factors associated with the two modes of delivery are the same, nor is there evidence whether the factors associated with the decision to perform a C-section are fundamentally medical or not if a trial of labor is conducted.

The results of this study show that the probability of a woman having a vaginal second delivery was lower among women with a higher family income, confirming the observations of other authors (12, 15). Moreover, poor educational level, perhaps indirectly associated with low socioeconomic status, has also been associated with a trial of labor, vaginal delivery and low C-section rates (16).

Socioeconomic status seems to be one of the most important factors in determining whether to perform a Csection $(2,12,17)$. Data obtained in 1984 for Brazil as a whole also reflected the trend toward more C-sections performed in higher-income families (18). A more recent analysis showed that the highest rates of C-section in Brazil occur-generally in private hospitalsin regions where economic improvements have been greatest (19). Type of health insurance is another determining factor in the mode of delivery. Brazilian statistics show that C-section rates vary enormously according to the type of health insurance. The lowest rates-around 30\%-occur in women receiving care in public hospitals and clinics, whereas in the private sector rates were above $50 \%(12-14,20)$. A recent evaluation detected some private hospitals in the state of São Paulo where rates were higher than $80 \%$ (19). Data from the USA and Canada are similar, showing C-section rates almost three times as high in women with private insurance coverage; however even these rates are lower than those found in Brazil $(2,15,21)$.

In addition to maternal age, parity is another factor that has an important influence on C-section rates. Primiparity seems to be more frequently associated with a C-section (22). The fact that higher $\mathrm{C}$-section rates were associated with private healthcare is in agreement with published data reporting that the main determining factor for performing a C-section is socioeconomic, particularly the socioeconomic status of women (3, 15, 18-20, 23). Medical factors seem to be less important in determining which women with a previous C-section will or will not be successful in a trial of labor and in achieving vaginal delivery.

Our results show that when the first C-section was indicated because of breech or transverse presentation or twin pregnancy, the rate of vaginal second delivery was higher. In fact, some indications for a first C-section, especially those with lower rates of recurrence, may be associated with a successful vaginal second delivery $(24,25)$.

Vaginal delivery did not modify the health status of the newborn. Our results show that there was no difference in neonatal health between the two modes of delivery $(26,27)$. It is important to emphasize that very strict monitoring of fetal well-being during labor is always recommended (2). Premature rupture of the membranes is often associated with vaginal delivery. Hueston and Rudy (23) demonstrated that this condition is also more frequently associated with a trial of labor in women who have had a previous C-section.

The rate of VBAC for the total study population was $11 \%$, and increased to $45 \%$ when a trial of labor occurred. On the other hand, among the women who had a second cesarean delivery, only $15 \%$ had undergone a trial of labor. These data show that a trial of labor is fundamental in achieving higher rates of vaginal delivery in women with a uterine scar, a finding in agreement with data published by other authors (27-29). In 1988 a movement was launched in the USA by the American College of Obstetricians and Gynecologists to implement and increase the practice of VBAC. Currently, some authors report trial of labor rates of around $80 \%$ in women with a previous C-section, and success rates of around $70 \%(6,9,10,24)$.

These considerations may suggest a simple mathematical exercise with potentially important practical implications for women's health and, indi- rectly, for the "financial health" of public and private institutions. If a trial of labor were permitted at second delivery for women with a previous C-section, around half of the women would achieve vaginal delivery, significantly reducing the rate of Csections along with their medical and economic consequences. According to the results of the present study, if the 1019 women who were not permitted to undergo a trial of labor in their second delivery had been allowed to do so, around $40 \%$ of them would have successfully delivered vaginally, i.e., there would have been an additional 408 vaginal second deliveries. This means that the current $11 \%$ rate of VBAC would have been increased to around $41 \%$. If we consider that these figures are representative of a relatively large city which can be considered similar to other populations in Brazil where socioeconomic level and $\mathrm{C}$-section rates are both high, their importance becomes clear.

There are some limitations to this study that should be pointed out. First of all, there is a possibility of recall bias, considering that the only source of information was the answers the women gave during interviews that took place in 1995. However, because neither the women nor the interviewers were aware of the hypothesis being tested at the interview, and because of the importance women generally place on factors associated with their deliveries, we consider recall bias to have been unlikely. Secondly, we consider that the possible limitations of the study design were compensated by the population-based approach to the study. The fact that these results are based on data collected in just one Brazilian city may be considered a limitation of this study since some regional differences do exist in terms of numbers and proportions. However, the majority of the female population in Brazil lives in urban areas such as Campinas, and the trends in delivery preferences are largely similar throughout the country; therefore this limitation is not likely to affect the applicability of our results to other regions (20). 
It seems probable that in the near future, ultrasound evaluation of lower uterine segment thickness will be used to predict the likelihood of achieving vaginal birth among women with a previous abdominal delivery scar (30). Taking these considerations into account, our retrospective analysis of data from a database can have practical implications. Our findings offer strong scientific arguments, from a population-based study, that it is pos- sible to achieve vaginal delivery in at least half the women who have had a previous C-section, and that vaginal delivery is safe if the outcome of a trial of labor is satisfactory. It seems clear that the increasing trend toward performing a C-section is not justifiable as a solely medical decision, but is becoming more akin to a fashion, i.e., something that can or cannot be bought depending predominantly on socioeconomic conditions.

\section{REFERENCES}

1. Katz VL, Cefalo RC. History and evolution of cesarean delivery. In: Phelan JP, Clark SL, eds. Cesarean Delivery. New York: Elsevier Science; 1988:1-18.

2. Shearer E. Cesarean section: medical benefits and costs. Soc Sci Med 1993; 37: 1223-31.

3. Faúndes A, Cecatti JG. Which policy for Caesarian sections in Brazil? An analysis of trends and consequences. Health Policy Plan 1993;8: 33-42.

4. Sachs BP, Yeh J, Acker D, Driscoll S, Brown DAJ, Jewett JF. Cesarean section related maternal mortality in Massachusets, 1954-1985. Obstet Gynecol 1988;71:385.

5. Petitti D, Cefalo RC, Shapiro BA, Whalley P. In-hospital maternal mortality in the United States: time trends and relation to method of delivery. Obstet Gynecol 1982;59:6-12.

6. Rosen MG, Dickinson JCB, Westhoff CL. Vaginal birth after cesarean: a meta analysis of morbidity and mortality. Obstet Gynecol 1991;77:465-70.

7. Menacker F, Curtin SC. Trends in cesarean birth and vaginal birth after previous cesarean, 1991-99. Natl Vital Stat Rep 2001; 49(13):1-16.

8. Flamm BL. Vaginal birth after caesarean (VBAC). Best Pract Res Clin Gynaecol 2001; 15(1):81-92.

9. Paul RH, Miller DA. Cesarean birth: how to reduce the rate. Am J Obstet Gynecol 1995; 172:1903-11.

10. Bais JM, van der Borden DM, Pel M, Bonsel GJ, Eskes M, van der Slikke HJ, et al. Vaginal birth after cesarean section in a population with a low overall caesarean section rate. Eur J Obstet Gynecol Reprod Biol 2001;96(2): 158-62.

11. Holt VL, Mueller BA. Attempt and success rates for vaginal birth after caesarean section in relation to complications of the previous pregnancy. Paediatr Perinat Epidemiol 1997; 11(Suppl 1):63-72.
12. Barros FC, Vaughan JP, Victora CG. Why so many caesarean sections? The need for a further policy change in Brazil. Health Policy Planning 1986;1:19-29.

13. Chacham AS, Perpétuo MIO. The incidence of caesarean deliveries in Belo Horizonte, Brazil: Social and Economic Determinants. Reproductive Health Matters 1998; 6(11):115-121.

14. Besteti Pires HM, Cecatti JG, Faúndes A. Fatores associados à prova de trabalho de parto em primíparas com uma cesárea anterior [Factors associated to the trial of labor among primipara women with one previous $\mathrm{Ce}$ sarean section]. Rev Saúde Publ 1999;33(4): 342-8.

15. Stafford RS. The impact of non-clinical factors on repeat cesarean section. JAMA 1991;265: 59-63.

16. Ridley RT, Davis PA, Bright JH, Sinclair D. What influences a woman to choose vaginal birth after cesarean? J Obstet Gynecol Neonatol Nurs 2002;31(6):665-72.

17. Goldman G, Pineault R, Potvin L, Blais R, Bilodeau $\mathrm{H}$. Factors influencing the practice of vaginal birth after cesarean section. Am J Public Health 1993;83:1104-8.

18. Barros FC, Vaughan JP, Victora CG, Huttly zil. The Lancet 1991;338:167-9.

19. Rattner D. Sobre a hipótese de estabilização das taxas de cesárea do Estado de São Paulo, Brasil [On the hypothesis of cesarean birth rate stabilization in southeastern, Brazill. Rev Saúde Pública 1996;30:19-33. Hopkins K, Souza MR, et al. Unwanted caesarean sections among public and private patients in Brazil: prospective study. BMJ 2001; 323:1155-8.

21. Wagner CL, Metts AK. Rates of successful vaginal delivery after cesarean for patients with private versus public insurance. J Perinatol 1999;19(1):14-8. SRA. Epidemic of Caesarean sections in Bra-

20. Potter JE, Berquó E, Perpétuo IHO, Leal OF,
Acknowledgments. We are grateful to The Ford Foundation for sponsoring the original study, and also to the WHO for providing additional financial support for this study. We would also like to thank the interviewers, data collection supervisors, research assistants and statistician, as well as the staff members at the primary schools in Campinas, who helped us identify and contact the women eligible for inclusion in this study.
22. Hueston WJ. Site-to-site variation in the factors affecting cesarean section rates. Arch Fam Med 1995;4:346-51.

23. Hueston WJ, Rudy M. Factors predicting elective repeat cesarean delivery. Obstet Gynecol 1994;83:741-4.

24. Gonen R, Tamir A, Degani S, Ohel G. Variables associated with successful vaginal birth after one cesarean section: a proposed vaginal birth after cesarean section score. Am J Perinatol 2004;21(8):447-53.

25. Troyer LR, Parisi VM. Obstetric parameters affecting success in a trial of labor: designation of a scoring system. Obstet Gynecol 1992; 167:1099-104.

26. Dodd J, Crowther C. Vaginal birth after Caesarean versus elective repeat Caesarean for women with a single prior Caesarean birth: a systematic review of the literature. Aust N Z J Obstet Gynecol 2004; 44(5): 387-91.

27. Durnwald C, Mercer B. Vaginal birth after Cesarean delivery: predicting success, risks of failure. J Matern Fetal Neonatal Med 2004; 15(6):388-93.

28. Van der Walt WA, Cronjé HS, Bam RH. Vaginal delivery after one cesarean section. Int J Gynecol Obstet 1994;46:271-7.

29. Stedman CM, Scudder SR, Joseph GF. Vaginal birth after cesarean delivery: a group practice's approach to minimizing failed trial of labor. Prim Care Update Obstet Gynecol 1998; 5(4):187-8.

30. Sen S, Malik S, Salhan S. Ultrasonographic evaluation of lower uterine segment thickness in patients of previous cesarean section. Int J Gynaecol Obstet 2004;87(3):215-9.

Manuscript received on 3 May 2004. Revised version accepted for publication on 22 April 2005. 
RESUMEN Objetivo. Determinar qué factores se asocian con el parto vaginal en mujeres que han tenido una cesárea.

\section{Factores relacionados con el parto vaginal en mujeres brasileñas con cesárea anterior}

Palabras clave
Métodos. Un estudio anidado de casos y testigos se llevó a cabo en forma de un análisis de datos secundarios procedentes de un estudio de cohorte - original, retrospectivo y de carácter poblacional- en mujeres que tuvieron su primer hijo en 1985 en la ciudad de Campinas, São Paulo, Brasil, y que fueron entrevistadas 10 años más tarde, en 1995. La población estudiada se compuso de 1352 mujeres cuyo primer hijo había nacido por cesárea y que también habían tenido como mínimo un parto posterior. El grupo de los casos (150 mujeres, o alrededor de 11\% de la muestra) estuvo integrado por mujeres que tuvieron su segundo parto por la vía vaginal, y el grupo testigo se compuso de 1202 mujeres que tuvieron su segundo parto por cesárea. Para cada uno de los posibles factores asociados se calcularon la razón de posibilidades y el intervalo de confianza de 95\%. Se aplicó la prueba de tendencias de ji al cuadrado para analizar las variables categóricas. Se usó una regresión multifactorial incondicionada para estimar las razones de posibilidades ajustadas correspondientes a cada factor asociado. Resultados. Los factores que mostraron una asociación estadísticamente significativa con el parto vaginal fueron un ingreso familiar mensual menor de cinco veces el salario mínimo mensual en el Brasil; depender del sistema nacional de salud brasileño para obtener atención sanitaria; poca edad materna; y una primera cesárea efectuada por presentación de nalgas o transversal, o por embarazo gemelar. Del grupo de mujeres que también tuvieron un segundo parto por cesárea, solamente $11 \%$ habían hecho un esfuerzo por tener un parto vaginal.

Conclusiones. El principal factor que determina el parto vaginal en mujeres que ya habían tenido una cesárea fue la presencia de factores sociales y económicos adversos.

Cesárea, parto vaginal después de cesárea, factores de riesgo, esfuerzo de parto.

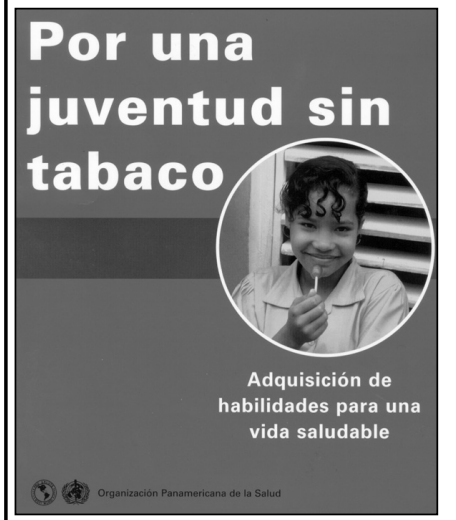

2001, 72p.,

ISBN 9275315795

Código: PC 579

Precios: US\$18.00/

US\$ 14.00 en América

Latina y el Caribe

\section{Por una juventud sin tabaco}

En la primera parte del libro se muestran los problemas fundamentales del consumo de tabaco, especialmente para la juventud. Se revisan temas relacionados con la prevención de las enfermedades relacionadas con el tabaco en los países de la Región y se describen los aspectos más eficaces de los diferentes métodos usados para su prevención. En la segunda, se presentan los enfoques teóricos y prácticos del programa de prevención del hábito de fumar conocido como "Habilidades para la vida", que alecciona a los jóvenes para que sean capaces de resistir las presiones sociales y de los medios de comunicación que los incitan a fumar.

Esta publicación está destinada a los profesionales de la salud, los planificadores de programas, los educadores, los encargados de formular las políticas y los grupos e instituciones que participan en la lucha contra el tabaquismo. En ella encontrarán información muy útil sobre la situación del tabaquismo en la Región, así como pautas para planificar y desarrollar programas de prevención del abuso de drogas, similares al de "Habilidades para la vida", que se adapten a las necesidades específicas de la Región y que sean un arma poderosa para la reducción de la carga evitable de muertes y discapacidades relacionadas con el tabaco. 